\title{
Anticancer Activities and QSAR Study of Novel Agents with a Chemical Profile of Benzimidazolyl-Retrochalcone
}

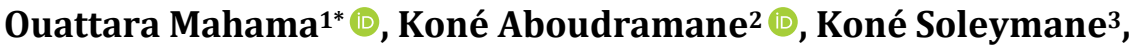 \\ Collet Sylvain ${ }^{4}$, Diomandé Sekou ${ }^{3}$, Sissouma Drissa ${ }^{3}$
}

\begin{abstract}
${ }^{1}$ Department of Therapeutic Chemistry and Organic Chemistry, UFR SPB, FHB University, Abidjan, Côte d'Ivoire ${ }^{2}$ Department of Chemistry, UFR Environment, Jean LorougnonGuédé University, Daloa, Côte d’Ivoire ${ }^{3}$ Laboratory of Organic Chemistry and Natural Substances, UFR SSMT, FHB University, Abidjan, Côte d'Ivoire ${ }^{4}$ Chemistry and Interdisciplinarity: Synthesis, Analysis, Modelling (CEISAM), University of Nantes, Nantes, France Email: ^mahama.ouattara@univ-fhb.edu.ci
\end{abstract}

How to cite this paper: Mahama, O., Aboudramane, K., Soleymane, K., Sylvain, C., Sekou, D. and Drissa, S. (2020) Anticancer Activities and QSAR Study of Novel Agents with a Chemical Profile of Benzimidazolyl-Retrochalcone. Open Journal of Medicinal Chemistry, 10, 113-127. https://doi.org/10.4236/ojmc.2020.103006

Received: July 18, 2020

Accepted: August 14, 2020

Published: August 17, 2020

Copyright ( 2020 by author(s) and Scientific Research Publishing Inc. This work is licensed under the Creative Commons Attribution International License (CC BY 4.0).

http://creativecommons.org/licenses/by/4.0/

(c) (i) Open Access

\begin{abstract}
The present pharmacochemical and modelling work focused on a benzimidazolyl-chalcone series. These previously synthesized compounds were evaluated in vitro for their anticancer activities against a panel of seven human cancer cell lines and normal fibroblasts. Among the new benzimidazole-supported chalcones, nine (9) compounds (compounds 1 - 4, 6 - 8 and compounds 10 and 11) showed promising anticancer activities with $\mathrm{IC}_{50} \mathrm{~s}$ ranging from 0.83 to $2.58 \mu \mathrm{M}$. Compounds 2 and 6 with $\mathrm{IC}_{50} \mathrm{~s}$ of 0.83 and 0.86 $\mu \mathrm{M}$, respectively, were shown to be potent inhibitors of HCT-116 colon cancer cell proliferation. It was therefore necessary, for a development of this new series of chalcones, to establish through a QSAR study, their quantum descriptors according to the DFT calculation method and following the B3LYP/6-31+G $(\mathrm{d}, \mathrm{p})$ theory. These descriptive and predictive studies focused on the colon HCT 116 cell line which was found to be more sensitive to the anticancer action of our benzimidazolyl-retrochalcones. QSAR study showed that the electronic energy $\left(E_{\text {elec }}\right)$, lipophilicity $(\log P)$, chemical softness $(S)$ and chemical hardness $(\eta)$ of benzimidazolyl-retrochalcones play an important role in inhibiting cancer cell proliferation.
\end{abstract}

\section{Keywords}

Retrochalcone, Benzimidazole, Anticancer Agents, QSAR, Quantum Descriptors, DFT Method 


\section{Introduction}

Cancer is characterized by a wide range of conditions involving abnormally large and unregulated cell proliferation in normal organism tissue. This proliferation can affect any part of the organism [1]. Cancer is currently a major cause of death worldwide. Indeed, it is the second leading cause of death, with 8.8 million deaths in 2015 according to the WHO [1] [2] [3]. Moreover, the growing economic impact of cancer is considerable. In 2010, the total annual cost of the disease was estimated to be approximately \$1.16 trillion (US \$) [4]. Among the main types of cancer that are fatal are lung, liver and colorectal cancer [1]. Chemotherapy treatment of cancer remains one of the preferred strategies for cancer management. Unfortunately, current cancer drugs are either ineffective for some people or too expensive for many populations.

It is in this perspective of contributing to the accessibility of new high-performance anti-cancer drugs that we have initiated this pharmacochemical and particularly a molecular modelling research [5] [6]. To this end, we have focused on 1,3-diphenylpropenones (chalcones) and the benzimidazole nucleus as pharmacophore and heterocyclic carrier, respectively. Indeed, taking into account their multiple intrinsic biological properties, it was normal to imagine that the combination of these chemical entities according to the concept of hybrid molecule, could generate new molecules likely to present new pharmacological activities, especially interesting anticancer ones.

Indeed, chalcones are an important class of compounds with antimalarial [7], anti-leishmaniac [8], antifungal [9] [10], antibacterial [11] [12] and anticancer [13] [14] [15] activities. Similarly, the benzimidazole-type diaza-heteroaryl is the pharmacophoric vector of numerous compounds with a broad spectrum of pharmacological activity, including anticancer [16], antiviral [17] [18], antibacterial [19] [20], anthelmintic [21] [22] and antifungal [23] activities.

Also, our benzimidazolyl-chalcones, which are actually retrochalcones, have been obtained in one of our previous work [24], by combining

$1 H$-benzimidazo-2-yl-carbaldehyde derivatives with various acetophenones and analogues. These novel retrochalcones were evaluated in vitro for their antitumor activity only on the NCI-H727 lung cancer cell line. In addition, their cytotoxicity was established in normal human skin fibroblast cells [24]. Taking into account our previous results on benzimidazolyl-chalcone series, in particular their anthelmintic and antifungal activities [25]-[30], as well as the first promising anticancer results in this retrochalcone series [24].

We propose in the present work, to extend their screening to six (06) other human cancer cell lines. The other objective of this work was to establish, by a QSAR study, the quantum descriptors according to the DFT calculation method and the B3LYP/6-31+G $(\mathrm{d}, \mathrm{p})$ theory and from the cancer line whose proliferation was most inhibited by our compounds. The aim of such a study was to lay the foundations for the development of new anticancer agents with a chemical profile of benzimidazolyl-retrochalcone. 


\section{Experimental Section}

\subsection{Chemistry}

We have recently published the synthesis and physico-chemical characteristics of the new series of benzimidazolyl-retrochalcone derivatives and their anticancer activity against human lung cancer cell line NCI-H727 [24]. The chemicalstructures of 13 of the benzimidazolyl-retrochalcone derivatives are reported in Table 1 [24].

Table 1. Chemical structures of benzimidazolyl-retrochalcone derivatives.

\begin{tabular}{|c|c|c|}
\hline Compound & $R_{5}$ & $R$ \\
\hline 1 & $\mathrm{H}$ & $\mathrm{H}$ \\
\hline 2 & $\mathrm{H}$ & $2-\mathrm{OH}$ \\
\hline 3 & $\mathrm{H}$ & $3-\mathrm{OH}$ \\
\hline 4 & $\mathrm{H}$ & $2-\mathrm{OCH}_{3}$ \\
\hline 5 & $\mathrm{H}$ & $4-\mathrm{NO}_{2}$ \\
\hline 6 & $\mathrm{H}$ & $\mathrm{H}$ \\
\hline 7 & $\mathrm{H}$ & $\mathrm{H}$ \\
\hline 8 & $\mathrm{Cl}$ & $\mathrm{H}$ \\
\hline 9 & $\mathrm{Cl}$ & $2-\mathrm{OH}$ \\
\hline 10 & $\mathrm{Cl}$ & $3-\mathrm{OH}$ \\
\hline 11 & $\mathrm{NO}_{2}$ & $2-\mathrm{OH}$ \\
\hline 12 & & $2-\mathrm{OH}$ \\
\hline 13 & & \\
\hline
\end{tabular}




\subsection{Biology}

\subsubsection{Cell Culture}

Skin normal fibroblastic cells were purchased from Lonza (Basel, Switzerland), HuH7, Caco-2, MDA-MB-231, MCF-7, HCT-116, PC3 and NCI-H727 cancer cell lines were obtained from the ECACC (European Collection Authenticated Cell Cultures) collection (Porton, UK).

Cells were grown according to ECACC recommendations in DMEM (Dulbecco's Modified Eagle's Medium) for HuH7, MDA-MB-231, MCF-7 and fibroblast, in EMEM (Eagle's Minimum Essential Medium) for CaCo-2, in McCoy's for HCT116 and in RPMI (Roswell Park Memorial Institute medium) for PC3, NCI-H727.

All culture media were added with $10 \%$ of FBS, $1 \%$ of penicillin-streptomycin and $2 \mathrm{mM}$ glutamine and were incubated at $37^{\circ} \mathrm{C}$ in a $5 \% \mathrm{CO}_{2}$ atmosphere.

\subsubsection{Cytotoxic Assay}

Chemicals were solubilized in DMSO at a concentration of $10 \mathrm{mM}$ (stock solution) and diluted in culture medium to the desired final concentrations.

The dose effect cytotoxic assays $\left(\mathrm{IC}_{50}\right.$ determination) were performed by increasing concentrations of each chemical (final well concentrations: $0.1 \mu \mathrm{M}-0.3$ $\mu \mathrm{M}-0.9 \mu \mathrm{M}-3 \mu \mathrm{M}-9 \mu \mathrm{M}-25 \mu \mathrm{M}$ ). Cells were plated in 96 wells ( 4000 cells/well).

Twenty-four hours after seeding, cells were exposed to chemicals. After $48 \mathrm{~h}$ of treatment, cells were washed in PBS and fixed in cooled $90 \%$ ethanol $/ 5 \%$ acetic acid for 20 minutes. Then, the nuclei were stained with Hoechst 33,342 (B2261 Sigma).

Image acquisition and analysis were performed using a Cellomics Array Scan VTI/HCS Reader (Thermo Scientific). The survival percentages were calculated as the percentage of cell number after compound treatment over cell number after DMSO treatment.

\subsection{QSAR and Theoretical Calculations}

\subsubsection{Materials and Methods of Calculation}

The nine (09) compounds of the training set and the four (04) other validation set used in this study, have their concentrations ranging from 0.83 to $8.86 \mu \mathrm{M}$. This range of concentrations makes it possible to define a quantitative relationship between the anticancer activity and the theoretical descriptors. Biological data are generally expressed as the opposite of the log 10 base of activity $\left(-\log _{10}(C)\right)$ in order to obtain higher mathematical values when the structures are biologically very efficient [31] [32].

\subsubsection{Level of Calculation}

The calculation to establish the relation between the biological activities values of the studied molecules and their molecular structures were obtained by quantum chemistry calculations using Gaussian software 09 [33]. DFT methods are generally known to generate a variety of molecular properties in QSAR studies 
[34]-[41]. These methods increase predictability, reduce computation time, and involve costs in the conception of new drugs [42] [43]. The B3LYP/6-31+G (d, p) theory level was used to determine the molecular descriptors. The modelling was done using the multilinear regression method implemented in Excel [44] and XLSTAT [45].

\subsubsection{Quantum Descriptors}

For the development of the QSAR model, fourteen theoretical descriptors have been calculated such as electronic energy $\left(E_{\text {elec }}\right)$, HOMO energy $\left(\varepsilon_{\text {номо }}\right)$, LUMO energy $\left(\varepsilon_{\text {номо }}\right)$, gap energy $(\Delta E)$, ionisation energy (IE), electronic affinity (EA), chemical hardness $(\eta)$, chemical softness $(S)$, electrophilicity $(\omega)$, chemical potential $\left(\mu_{p o t}\right)$, electronegativity $(\chi)$, dipole moment $(\mu)$, polarizability $(\alpha)$ and lipophilicity $(\log P)$. Among these descriptors, the combination of four of them permitted to establish a good model. We have the electronic energy $\left(E_{\text {elec }}\right)$, the chemical softness $(S)$, the chemical hardness $(\eta)$ and the lipophilicity $(\log P)$. The electronic energy $\left(E_{\text {electr }}\right)$ represents the electronic contribution of all atoms in a given molecule. The chemical softness $(S)$ indicates the capacity of an atom or a molecule to conserve an acquired charge [46] [47]. The higher the chemical softness, the less stable the molecule. The chemical hardness $(\eta)$ is a measure of stability of the molecule [48]. Lipophilicity is an important measure for the identification of the similarity with a drug [49]. All these descriptors are determined from optimized molecules follow by frequency calculation. The calculation of the partial correlation coefficient between the descriptors studied is less than $0.70\left(a_{i j}<0.70\right)$; which means that these different descriptors are independent of each other [50].

\subsubsection{Estimation of the Predictive Ability of a QSAR Model}

The quality of a model is determined according to certain criteria such as the coefficient of determination $R^{2}$, the standard deviation $S$, the correlation coefficients of cross-validation $Q_{C V}^{2}$ and Fischer coefficient $F$. The statistical indicators $R^{2}, S$ and $F$ relate to the adjustment of calculated and experimental values. They describe the predictive capacity within the model limits and allow estimating the precision of values calculated on the training set [51] [52]. The cross-validation coefficient gives information on the predictive power of the model. The coefficients $R^{2}$ express the dispersion of theoretical values around the experimental ones. The quality of a model is better when the points are close to the adjustment line [53]. The adjustment of the points to the line can be evaluated by the coefficient of determination.

$$
R^{2}=1-\frac{\sum\left(y_{i, \exp }-\hat{y}_{i, \text { theo }}\right)^{2}}{\sum\left(y_{i, \exp }-\bar{y}_{i, \text { exp }}\right)^{2}}
$$

$y_{i, e x p}:$ Experimental value of anticancer activity

$\hat{y}_{i, \text { theo }}$ : Theoretical value of anticancer activity

$\bar{y}_{i, \text { exp }}$ : The mean of the experimental values of anticancer activity 
The closer the value of $R^{2}$ to 1 , the more the theoretical and experimental values are correlated. In addition, the variance $\sigma^{2}$ is determined by the following relationship (2):

$$
\sigma^{2}=S^{2}=\frac{\sum\left(y_{i, \exp }-y_{i, \text { theo }}\right)^{2}}{n-k-1}
$$

where $k$ is the number of independent variables (descriptors) is, $n$ the number of molecules in the test or learning set and $n-k-1$ the degree of freedom. The standard deviation $S$ is another statistical indicator used to evaluate the reliability and precision of a model:

$$
S=\sqrt{\frac{\sum\left(y_{i, \text { exp }}-y_{i, t h e o}\right)^{2}}{n-k-1}}
$$

The Fischer coefficient $F$ is also used to express the level of statistical significance of the model, that is to say the quality of the choice of the descriptors constituting the model.

$$
F=\frac{\sum\left(y_{i, \text { theo }}-y_{i, \text { exp }}\right)^{2}}{\sum\left(y_{i, \text { exp }}-y_{i, \text { theo }}\right)^{2}} * \frac{n-k-1}{k}
$$

The coefficient of determination of cross-validation $Q_{C V}^{2}$, which allows evaluating the accuracy of the prediction on the test set and is calculated by using the following equation:

$$
Q_{C V}^{2}=\frac{\sum\left(y_{i, \text { theo }}-\bar{y}_{i, \text { exp }}\right)^{2}-\sum\left(y_{i, \text { theo }}-y_{i, \text { exp }}\right)^{2}}{\sum\left(y_{i, \text { theo }}-\bar{y}_{i, \text { exp }}\right)^{2}}
$$

The performance of a model, according to Eriksson et al. [54] is characterized by a value of $Q_{C V}^{2}>0.5$ for a satisfactory model when for the excellent model $Q_{C V}^{2}$ is higher than 0.9. A training set of a model will perform well if the acceptance criterion $R^{2}-Q_{C V}^{2}<0.3$ is respected. Moreover, the predictive power of a model can be obtained from the value of the $\log (1 / C)_{\text {theo }} / \log (1 / C)_{\exp }$ ratio for the test set. The model is acceptable when the value of the ratio of theoretical and experimental activity tends towards unity.

\section{Results and Discussion}

\subsection{Pharmacochemical Section}

All retrochalcone derivatives (compound 1 - 13) were evaluated for their anticancer activities in vitro on a cell panel. This is represented by seven (07) human cancer cell lines gathering in five (05) types cancer and skin normal fibroblastic cells. The products Roscovitine and Paclitaxel were used as positive anticancer controls. The results obtained are reported in Table 2 . The results of the anticancer activities expressed in $\mathrm{IC}_{50}(\mu \mathrm{M})$ showed that most retrochalcones exhibit strong antitumor activity in all cell lines. These compounds also showed cytotoxicity to normal fibroblasts with $\mathrm{IC}_{50}$ values ranging from 0.61 to $9.29 \mu \mathrm{M}$. 
Table 2. In vitro anticancer activities of benzimidazolyl-retrochalcones against cancer cell lines and normal human fibroblasts.

\begin{tabular}{|c|c|c|c|c|c|c|c|c|}
\hline \multirow{3}{*}{$\begin{array}{l}\text { Compound } \\
\text { Cancer } \\
\text { Cell lines }\end{array}$} & \multicolumn{8}{|c|}{ In vitro anticancer activities of benzimidazolyl-retrochalcones $\left(\mathrm{IC}_{50}\right.$ at $\left.\mu \mathrm{M}\right)$} \\
\hline & \multirow{2}{*}{$\begin{array}{c}\text { Hepatitis } \\
\text { Huh-7 }\end{array}$} & \multirow{2}{*}{$\begin{array}{c}\text { Prostate } \\
\text { PC3 }\end{array}$} & \multirow{2}{*}{$\begin{array}{c}\begin{array}{c}\text { Non-small } \\
\text { cell lung }\end{array} \\
\text { NCI-H727 } \\
{[24]}\end{array}$} & \multicolumn{2}{|c|}{ Colon } & \multicolumn{2}{|c|}{ Breast } & \multirow{2}{*}{ Fibroblast } \\
\hline & & & & $\mathrm{CaCo} 2$ & HCT-116 & $\begin{array}{c}\text { MDA-MB } \\
231\end{array}$ & MCF-7 & \\
\hline 1 & 7.77 & 4.17 & 2.83 & 5.25 & 1.48 & 3.92 & 5.02 & 4.60 \\
\hline 2 & 2.17 & 1.08 & 1.54 & 1.32 & 0.83 & 1.13 & 1.56 & 0.91 \\
\hline 3 & 4.02 & 3.01 & 3.15 & 2.64 & 2.73 & 2.58 & 3.22 & 2.00 \\
\hline 4 & 2.91 & 1.83 & 2.20 & 2.16 & 2.39 & 1.35 & 2.57 & 0.61 \\
\hline 5 & 11.26 & 9.57 & 8.63 & 10.73 & 8.01 & 12.60 & 7.71 & 5.88 \\
\hline 6 & 4.35 & 2.32 & 1.98 & 3.58 & 0.86 & 1.61 & 2.80 & 2.91 \\
\hline 7 & 2.05 & 2.59 & 2.50 & 2.69 & 1.92 & 1.42 & 4.70 & 3.15 \\
\hline 8 & 7.64 & 2.67 & 2.71 & 4.06 & 4.99 & 2.80 & 2.50 & 7.54 \\
\hline 9 & 8.83 & 4.03 & 4.89 & 4.16 & 7.48 & 7.44 & 2.91 & 4.71 \\
\hline 10 & 4.54 & 3.13 & 2.82 & 3.32 & 3.92 & 2.26 & 3.60 & 3.23 \\
\hline 11 & 6.77 & 1.78 & 3.59 & 4.09 & 4.76 & 4.32 & 3.57 & 8.02 \\
\hline 12 & 8.46 & 3.89 & 4.61 & 5.52 & 3.66 & 6.56 & 5.45 & 5.95 \\
\hline 13 & 5.17 & 14.70 & 6.35 & 9.88 & 8.86 & 9.73 & 4.52 & 9.29 \\
\hline Roscovitine & 16 & 11 & 16 & 17 & 8 & 18 & 11 & 3 \\
\hline Paclitaxel & 0.01 & 0.001 & 0.002 & 0.03 & 0.004 & 0.04 & 0.01 & $>0.25$ \\
\hline
\end{tabular}

Except compounds 5, 9, 12 and 13 all other benzimidazolyl-retrochalcones showed better anticancer activity compared to the performance of the Roscovitine. However, Paclitaxel remains by far the most effective drug by any cell line. In particular, the conformational blocking of the functional enchainment propenone with phenolic $\mathrm{OH}$ in a coumarin-like ring (compounds 13), did not induce excellent activity.

For the retrochalcones that showed promising anticancer activities, we can note that they carry on their benzene ring (Ar) either a hydroxyl group or a methoxyl group in isomeric position 2 or 3 (compounds 2, 3 and 4). When this benzene ring is unsubstituted (compound 1), the activity obtained is moderate against all tumour cell lines with $\mathrm{IC}_{50}$ values ranging from 1.48 to $7.77 \mu \mathrm{M}$. Also, the replacement of benzene ring by furanyl (compound 6) and benzimidazolyl (compound 7) heterocycles type showed better activities than retrochalcone 1. However, compound 5 substituted with nitro group, led to a significant decline in anticancer activities compared to compound $\mathbf{1}$.

The C-5 substitution of benzimidazole with a chlorine, nitro or benzoyl group does not involve an increase in anticancer activities compared to the non-C-5 benzimidazole substituted (compound 1 ). The compound $\mathbf{2}$ with hydroxyl group in position 2 in benzene ring, has been particularly effective against prostate, 
colon (HCT-116) and breast (MDA-MB 231) cancer cell lines with $\mathrm{IC}_{50}$ values of $1.08,0.83$ and $1.13 \mu \mathrm{M}$ respectively. Biological activities on colon cancer (HCT-116) have been used to establish the QSAR's model.

\subsection{QSAR and Theoretical Calculations Section}

\subsubsection{Training and Validation Set}

The results of training set of nine (09) benzimidazolyl-retrochalcones and the four (04) molecules of the validation set are reported in Table 3. As for Table 4, it presents the values of partial correlation coefficients $a_{i j}$ of the descriptors.

The partial correlation $a_{i j}$ between the descriptors is less than 0.70 . This shows the independence of the descriptors used in the model.

\subsubsection{QSAR Model Validation}

The positive and the negative sign of the descriptor's coefficient of the model reflects the proportionality's effect between anticancer activity evolution and descriptors of the regression equation. A positive sign shows that the descriptor influencing positively the activity. Then, the negative sign indicates the opposite effect.

Table 3. Training set of nine (09) molecules and the four (04) molecules of the validation set associated with the molecular descriptors and anticancer activity (HTC-116).

\begin{tabular}{ccccccc}
\hline Compounds & $\mathrm{IC}_{50}(\mu \mathrm{M})$ & $\log (1 / C)_{\text {exp }}$ & $E_{\text {elec }}\left(\mathrm{kcal} \cdot \mathrm{mol}^{-1}\right)$ & $S(\mathrm{ev})^{-1}$ & $\eta(\mathrm{ev})$ & $\log P$ \\
\hline $\mathbf{1}^{*}$ & 1.48 & 5.83 & $-503,090.71$ & 0.48 & 2.07 & 3.49 \\
2 & 0.83 & 6.08 & $-550,302.87$ & 0.56 & 1.79 & 3.47 \\
$3^{*}$ & 2.73 & 5.56 & $-550,304.48$ & 0.56 & 1.77 & 2.83 \\
4 & 2.39 & 5.62 & $-574,966.71$ & 0.55 & 1.81 & 2.38 \\
5 & 8.01 & 5.10 & $-631,432.82$ & 0.65 & 1.55 & 3.45 \\
$6^{*}$ & 0.86 & 6.07 & $-704,381.21$ & 0.57 & 1.77 & 3.09 \\
7 & 1.92 & 5.72 & $-595,743.39$ & 0.60 & 1.67 & 3.40 \\
8 & 4.99 & 5.30 & $-791,507.03$ & 0.56 & 1.80 & 4.08 \\
9 & 7.48 & 5.13 & $-838,711.52$ & 0.55 & 1.81 & 4.07 \\
$10^{*}$ & 3.92 & 5.41 & $-838,712.89$ & 0.56 & 1.80 & 3.43 \\
11 & 4.76 & 5.32 & $-678,639.32$ & 0.53 & 1.87 & 3.20 \\
12 & 3.66 & 5.44 & $-766,425.19$ & 0.55 & 1.83 & 4.43 \\
13 & 8.86 & 5.05 & $-549,551.59$ & 0.49 & 2.06 & 2.81 \\
\hline
\end{tabular}

*Validation set of the model.

Table 4. Values of partial correlation coefficients of the descriptors.

\begin{tabular}{ccccc}
\hline Descriptors & $E_{\text {elec }}\left(\mathrm{kcal} \cdot \mathrm{mol}^{-1}\right)$ & $\eta(\mathrm{ev})$ & $S(\mathrm{ev})^{-1}$ & $\log P$ \\
\hline$E_{\text {elec }}$ & 1 & 0.53 & 0.51 & -0.64 \\
$\eta$ & 0.53 & 1 & -0.99 & 0.26 \\
$S$ & 0.51 & -0.99 & 1 & 0.25 \\
$\log P$ & -0.64 & 0.26 & 0.25 & 1
\end{tabular}


The best QSAR models obtained for anticancer activity against HCT-116 colon cancer is given by the following relationship: $\log (1 / C)=79.684+3.896 \mathrm{E}-06$

${ }^{\star} E_{\text {elec }}\left(\mathrm{kcal} \cdot \mathrm{mol}^{-1}\right)-20.469 * \eta(\mathrm{ev})-64.245 * S(\mathrm{ev})^{-1}+0.301 * \log P$.

The statistical indicators of multilinear regression are shown in Table 5.

The electronic energy $\left(E_{\text {elec }}\right)$ and the lipophilicity $(\log P)$ have a positive sign in the model, which suggest that increased activity can be achieved by increasing the electronic energy and the lipophilicity.

The chemical hardness $(\eta)$ and the chemical softness $(S)$ have a negative sign in the model, which suggest that increased activity can be achieved by decreasing the chemical hardness and softness. A good model is qualified by its high value of the coefficient of Fischer $F=170.803$, the cross-validation coefficient $Q_{C V}^{2}$ which is 0.954 . The values of $\log (1 / C)_{\text {theo }} / \log (1 / C)_{\exp }$ ratio of external validation set are shown in Table 6.

All values of $\log (1 / C)_{\text {theo }} / \log (1 / C)_{\text {exp }}$ tend to 1 . This indicates the good correlation between the theoretical and experimental anticancer activity of the molecules studied. The regression line between the experimental and theoretical anticancer activity of training set (blue dots) and the test set (red dots) is illustrated in Figure 1.

\subsubsection{Analysis of the Contribution of Descriptors in the Model}

The relative contribution of the descriptors in the prediction of anticancer activity of the molecules is shown in Figure 2.

The chemical hardness $(\eta)$ and the chemical softness $(S)$ have a wide contribution. The lipophilicity presents a weak contribution.

Table 5. Statistical indicators of multilinear regression.

\begin{tabular}{cc}
\hline Statistical indicators of multilinear regression & HCT-116 \\
\hline Number of compounds $N$ & 9 \\
Coefficient of determination $R^{2}$ & 0.99 \\
Correlation coefficient of cross-validation $Q_{c V}^{2}$ & 0.95 \\
Standard deviation $S$ & 0.52 \\
Fischer coefficient $F$ & 170.80 \\
$R^{2}-Q_{c V}^{2}$ & 0.04
\end{tabular}

Table 6. Values of the relationship between theoretical and experimental anticancer activity of validation set.

\begin{tabular}{cccc}
\hline Compounds & $\log (1 / C)_{\text {theo }}$ & $\log (1 / C)_{\text {exp }}$ & $\frac{\log (1 / C)_{\text {theo }}}{\log (1 / C)_{\text {exp }}}$ \\
\hline 1 & 5.35 & 5.83 & 0.9 \\
3 & 5.86 & 5.56 & 1.1 \\
6 & 5.34 & 6.07 & 0.9 \\
10 & 4.91 & 5.41 & 0.9 \\
\hline
\end{tabular}




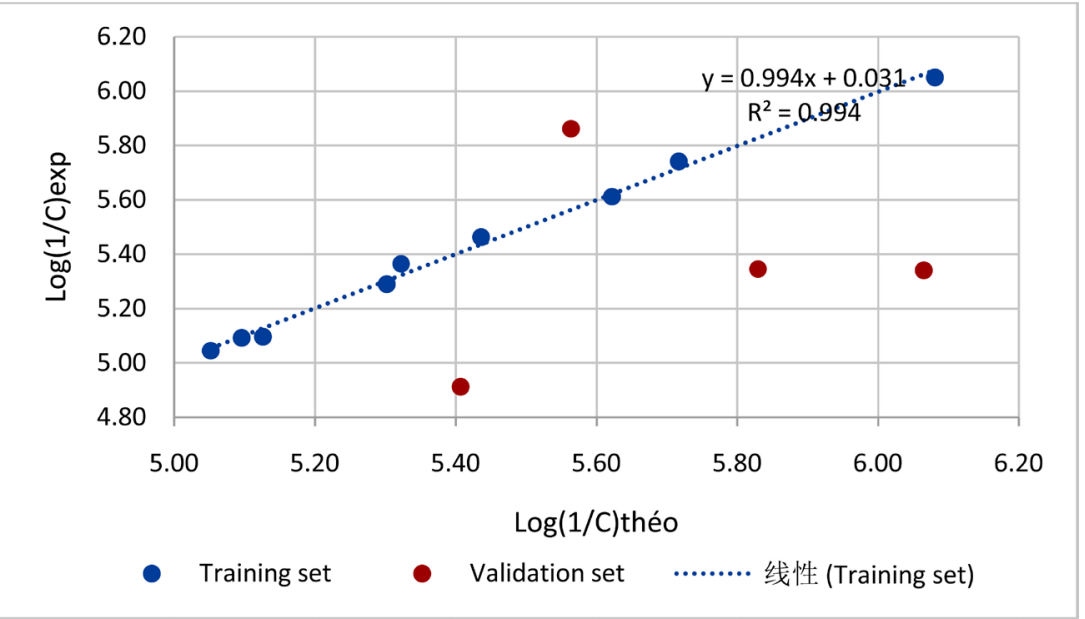

Note: The mathematical model used for the theoretical calculations is only valid for the benzimidazolyl-retrochalcone series.

Figure 1. Regression line of the model.

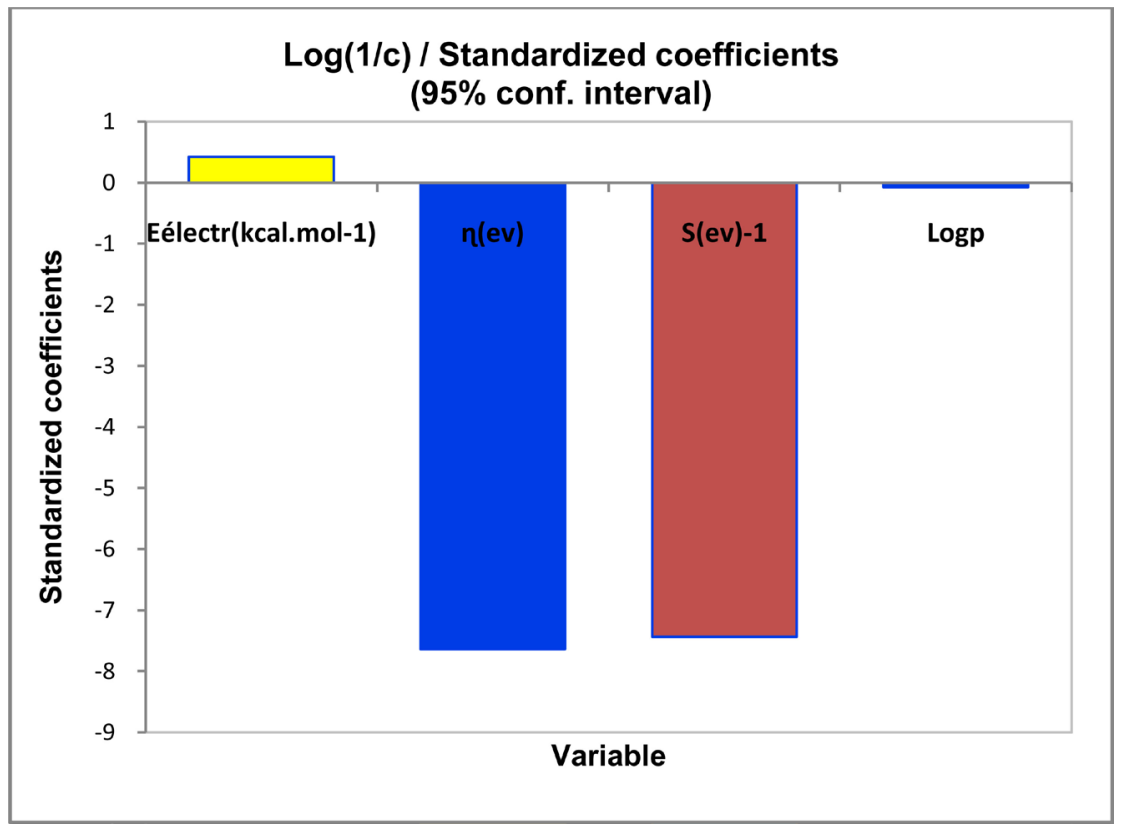

Figure 2. Contribution of different descriptors.

\section{Conclusion}

In this work, we evaluated a series of benzimidazolyl-retrochalcone derivatives for their in vitro cytotoxic activity against a panel of seven (7) human cancer cell lines including hepatitis cancer (Huh-7), prostate cancer (PC3), non-small cell lung cancer (NCI-H727), colon cancer (CaCo2, HCT-116), breast cancer (MDA-MB 231, MCF-7) and a normal fibroblast cell of human skin. Benzimidazolyl-retrochalcone showed promising anticancer activities with $\mathrm{IC}_{50}$ values ranging from 0.83 to $14.70 \mu \mathrm{M}$ and also proved to be less toxic than the reference molecule Paclitaxel and Roscovitine. Among these, compounds 2 and 6 were found to be more effective against colon cancer (HCT-116) with $\mathrm{IC}_{50}$ values of 
0.83 and $0.86 \mu \mathrm{M}$ respectively. QSAR study undertaken to establish a relationship between the anticancer activities on the colon cell line (HCT-116) and the chemical profile of the thirteen (13) benzimidazolyl-retrochalcone derivatives, showed a good correlation with the theoretical descriptors calculated by the DFT method. Thus, electronic energy $\left(E_{\text {elec }}\right)$, lipophilicity $(\log P)$, chemical softness $(S)$ and chemical hardness $(\eta)$ play an important role in the induction of antitumor activities of retrochalcones. Negative signs of chemical sweetness $(S)$ and chemical hardness $(\eta)$ increase anticancer activity. Our QSAR model thus shows that it is possible to predict and especially increase the cytotoxicity of the benzimidazolyl-retrochalcones against the colon cancer cell line (HCT-116).

\section{Acknowledgements}

The authors express their deep thanks to Campus France and AMRUGE-CI/C2D for financial support. We are very grateful to Dr Rémy Le Guével, responsible for the platform "ImPACcelP' of Rennes 1 university, for anticancer assay in human cell lines.

\section{Conflicts of Interest}

The authors declare no conflicts of interest regarding the publication of this paper.

\section{References}

[1] WHO (2020). https://www.who.int/fr/news-room/fact-sheets/detail/cancer

[2] Torre, L.A., Bray, F., Siegel, R.L., Ferlay, J., Lortet-Tieulent, J. and Jemal, A. (2015) Global Cancer Statistics, 2012. CA: A Cancer Journal for Clinicians, 65, 87-108. https://doi.org/10.3322/caac.21262

[3] Ferlay, J., Soerjomataram, I., Dikshit, R., Eser, S., Mathers, C., Rebelo, M., Parkin, D.M., Forman, D. and Bray, F. (2015) Cancer Incidence and Mortality Worldwide: Sources, Methods and Major Patterns in GLOBOCAN 2012. International Journal of Cancer, 136, E359-E386. https://doi.org/10.1002/ijc.29210

[4] Stewart, B.W. and Wild, C.P. (2014) World Cancer Report 2014. International Agency for Research on Cancer, Lyon.

http://file:///C:/Users/Admin/Downloads/World\%20Cancer\%20Report\%209789283 204435.pdf

[5] N’Guessan, K.N., Guy-Richard Koné, M., Bamba, K., Wawohinlin Patrice, O. and Ziao, N. (2017) Quantitative Structure Anticancer Activity Relationship (QSAR) of a Series of Ruthenium Complex Azopyridine by the Density Functional Theory (DFT) Method. Computational Molecular Bioscience, 7, 19-31. https://doi.org/10.4236/cmb.2017.72002

[6] N’Dri, J.S., Kablan, A.L., Ouattara, B., Koné, M.G., Ouattara, L.P., Kodjo, C.G. and Ziao, N. (2019) QSAR Studies of the Antifungal Activities of $\alpha$-Diaminophosphonates Derived from Dapsone by DFT Method. Journal of Materials Physics and Chemistry, 7, 1-7.

[7] Chen, M., Theander, T.G., Christensen, S.B., Hviid, L., Zhai, L. and Kharazmi, A. (1994) Licochalcone A, a New Antimalarial Agent, Inhibits in Vitro Growth of the Human Malaria Parasite Plasmodium falciparum and Protects Mice from $P$. yoelii 
Infection. Antimicrobial Agents and Chemotherapy, 38, 1470-1475.

https://doi.org/10.1128/AAC.38.7.1470

[8] Boeck, P., Bandeira Falcão, C.A., Leal, P.C., Yunes, R.A., Filho, V.C., Torres-Santos, E.C. and Rossi-Bergmann, B. (2006) Synthesis of Chalcone Analogues with Increased Antileishmanial Activity. Bioorganic and Medicinal Chemistry, 14, 1538-1545. https://doi.org/10.1016/j.bmc.2005.10.005

[9] ElSohly, H.N., Joshi, A.S., Nimrod, A.C., Walker, L.A. and Clark, A.M. (2001) Antifungal Chalcones from Macluratinctoria. Plantamedica, 67, 87-89. https://doi.org/10.1055/s-2001-10621

[10] Boeck, P., Leal, P.C., Yunes, R.A., Filho, V.C., López, S., Sortino, M., Escalante, A., Furlán, R.L. and Zacchino, S. (2005) Antifungal Activity and Studies on Mode of Action of Novel Xanthoxyline-Derived Chalcones. Archiv der Pharmazie, 338, 87-95. https://doi.org/10.1002/ardp.200400929

[11] Haraguchi, H., Tanimoto, K., Tamura, Y., Mizutani, K. and Kinoshita, T. (1998) Mode of Antibacterial Action of Retrochalcones from Glycyrrhizainflata. Phytochemistry, 48, 125-129. https://doi.org/10.1016/S0031-9422(97)01105-9

[12] Nielsen, S.F., Larsen, M., Boesen, T., Schønning, K. and Kromann, H. (2005) Cationic Chalcone Antibiotics. Design, Synthesis, and Mechanism of Action. Journal of medicinal chemistry, 48, 2667-2677. https://doi.org/10.1021/jm049424k

[13] Kamal, A., Prabhakar, S., JanakiRamaiah, M., Venkat Reddy, P., Ratna Reddy, C.H., Mallareddy, A., Shankaraiah, N., Lakshmi Narayan Reddy, T., Pushpavalli, S.N. and Pal-Bhadra, M. (2011) Synthesis and Anticancer Activity of Chalcone-Pyrrolobenzodiazepine Conjugates Linked via 1,2,3-Triazole Ring Side-Armed with Alkane Spacers. European Journal of Medicinal Chemistry, 46, 3820-3831. https://doi.org/10.1016/j.ejmech.2011.05.050

[14] Syam, S., Abdelwahab, S.I., Al-Mamary, M.A. and Mohan, S. (2012) Synthesis of Chalcones with Anticancer Activities. Molecules (Basel, Switzerland), 17, 6179-6195. https://doi.org/10.3390/molecules17066179

[15] Wei, H., Zhang, X., Wu, G., Yang, X., Pan, S., Wang, Y. and Ruan, J. (2013) Chalcone Derivatives from the Fern Cyclosorusparasiticus and Their Anti-Proliferative Activity. Food and Chemical Toxicology, 60, 147-152. https://doi.org/10.1016/j.fct.2013.07.045

[16] Abdel-Mohsen, H.T., Ragab, F.A., Ramla, M.M. and El Diwani, H.I. (2010) Novelbenzimidazole-Pyrimidine Conjugates as Potentantitumor Agents. European Journal of Medicinal Chemistry, 45, 2336-2344. https://doi.org/10.1016/j.ejmech.2010.02.011

[17] Garuti, L., Roberti, M. and De Clercq, E. (2002) Synthesis and Antiviral/Antiproliferative Activity of Some N-sulphonylbenzimidazoles. Bioorganic \& Medicinal Chemistry Letters, 12, 2707-2710.

https://doi.org/10.1016/S0960-894X(02)00535-8

[18] Hwu, J.R., Singha, R., Hong, S.C., Chang, Y.H., Das, A.R., Vliegen, I., De Clercq, E. and Neyts, J. (2008) Synthesis of New Benzimidazole-Coumarin Conjugates as Anti-Hepatitis C Virus Agents. Antiviral Research, 77, 157-162. https://doi.org/10.1016/j.antiviral.2007.09.003

[19] He, Y., Yang, J., Wu, B., Risen, L. and Swayze, E.E. (2004) Synthesis and Biological Evaluations of Novel Benzimidazoles as Potential Antibacterial Agents. Bioorganic \& Medicinal Chemistry Letters, 14, 1217-1220. https://doi.org/10.1016/j.bmcl.2003.12.051

[20] Güven, O.O., Erdoğan, T., Göker, H. and Yildiz, S. (2007) Synthesis and Antimicro- 
bial Activity of Some Novel Phenyl and Benzimidazole Substituted Benzyl Ethers. Bioorganic \& Medicinal Chemistry Letters, 17, 2233-2236. https://doi.org/10.1016/j.bmcl.2007.01.061

[21] Mavrova, A., Anichina, K.K., Vuchev, D.I., Tsenov, J.A., Kondeva, M.S. and Micheva, M.K. (2005) Synthesis and Antitrichinellosis Activity of Some 2-substituted-[1,3]thiazolo[3,2-a]benzimidazol-3(2H)-ones. Bioorganic \& Medicinal Chemistry, 13, 5550-5559. https://doi.org/10.1016/j.bmc.2005.06.046

[22] Mavrova, A., Anichina, K.K., Vuchev, D.I., Tsenov, J.A., Denkova, P.S., Kondeva, M.S. and Micheva, M.K. (2006) Antihelminthic Activity of Some Newly Synthesized 5(6)-(un)substituted-1H-benzimidazol-2-ylthioacetylpiperazine Derivatives. European Journal of Medicinal Chemistry, 41, 1412-1420. https://doi.org/10.1016/j.ejmech.2006.07.005

[23] Göker, H., Kuş, C., Boykin, D.W., Yildiz, S. and Altanlar, N. (2002) Synthesis of Some New 2-Substituted-phenyl-1H-benzimidazole-5-carbonitriles and Their Potent Activity against Candida Species. Bioorganic \& Medicinal Chemistry, 10, 2589-2596. https://doi.org/10.1016/S0968-0896(02)00103-7

[24] Kone, A., Ouattara, M., Zon, D., Chany, A., Collet, S., Sissouma, D. and Adjou, A. (2018) Synthesis and Cytotoxic Activities of 3-Benzimidazolyl-Chalcones Derivatives. World Journal of Pharmaceutical Research, 7, 1589-1601.

[25] Ouattara, M., Sissouma, D., Koné, M.W., Menan, H., Touré, S.A. and Ouattara, L. (2011) Synthesis and Anthelmintic Activity of Some Hybrid Benzimidazolyl-Chalcone Derivatives. Tropical Journal of Pharmaceutical Research, 10, 767-775. https://doi.org/10.4314/tjpr.v10i6.10

[26] Sissouma, D., Ouattara, M., Zon, D. and Kone, M.W. (2015) Synthesis and Antifungal Activities of Some Benzimidazolyl-Chalcones, Analogues of Chlormidazole. African Journal of Pharmacy and Pharmacology, 9, 418-423. https://doi.org/10.5897/AJPP2014.4171

[27] Ouattara, M., Sissouma, D., Yavo, W. and Kone, M.W. (2015) Synthèse et criblageantiplasmodial de quelquesbenzimidazolyl-chalcones. International Journal of Biological and Chemical Sciences, 9, 1697-1710. https://doi.org/10.4314/ijbcs.v9i3.48

[28] Songuigama, C., Jean-Paul, N.D., Mamidou, K.W., Drissa, S. and Mahama, O. (2018) Anti-Candidosi Activities of New Chalcones Vectorised by Benzimidazole against a Strain of Candida albicans Pharmacoresistance to Azoles. IOSR Journal of Pharmacy and Biological Sciences, 13, 11-16.

[29] Songuigama, C., et al. (2019) Synthesis and Antifungal Activities of Benzimidazolyl-Arylpropenone Scaffolds as Promising Inhibitors of Azole-Resistant Candida Strains. European Journal of Biomedical and Pharmaceutical Sciences, 6, 19-25.

[30] Mahama, O., Jean-Paul, N.D., Songuigama, C., Drissa, S. and Mamidou, K.W. (2020) Design and Pharmacochemical Development of New Anthelmintics with Benzimidazolyl Arylpropenone Profile: Structure-Activity Relationship. Pharmacophore, 11, 58-66.

[31] Chatterjee, S., Hadi, A.S. and Price, B. (2000) Regression Analysis by Example. Wiley, New York.

[32] ThiNgocPhuong Huynh (2007) Synthèse et études des relations structure/activité quantitatives (QSAR/2D) d'analyse benzo[c]phénanthridiniques. Sciences du Vivant [q-bio]. Universitéd'Angers, Français.

[33] Frisch, M.J., Trucks, G.W., Schlegel, H.B., Scuseria, G.E., Robb, M.A., Cheeseman, J.R., et al. (2009) Gaussian 09, Revision A.02. Gaussian, Inc., Wallingford. 
[34] Chattaraj, P.K., Cedillo, A. and Parr, R.G. (1995) Variational Method for Determining the Fukui Function and Chemical Hardness of an Electronic System. The Journal of Chemical Physics, 103, 7645-7646. https://doi.org/10.1063/1.470284

[35] Ayers, P.W. and Parr, R.G. (2000) Variational Principles for Describing Chemical Reactions: The Fukui Function and Chemical Hardness Revisited. Journal of the American Chemical Society, 122, 2010-2018. https://doi.org/10.1021/ja9924039

[36] De Proft, F., Martin, J.M.L. and Geerlings, P. (1996) On the Performance of Density Functional Methods for Describing Atomic Populations, Dipole Moments and Infrared Intensities. Chemical Physics Letters, 250, 393-401. https://doi.org/10.1016/0009-2614(96)00057-7

[37] Geerlings, P., De Proft, F. and Martin, J.M.L. (1996) Recent Developments in Density Functional Theory. In: Seminario, J., Ed., Theoretical and Computational Chemistry, Elsevier, Amsterdam, Vol. 4, 773.

https://doi.org/10.1016/S1380-7323(96)80103-8

[38] De Proft, F., Martin, J.M.L. and Geerlings, P. (1996) Calculation of Molecular Using Density Functional Methods. Chemical Physics Letters, 256, 400-408. https://doi.org/10.1016/0009-2614(96)00469-1

[39] De Proft, F. and Geerlings, P. (1997) Calculation of Ionization Energies, Electron Affinities, Electronegativities, and Hardnesses Using Density Functional Methods. The Journal of Chemical Physics, 106, 3270-3279. https://doi.org/10.1063/1.473796

[40] Geerlings, P., De Proft, F. and Langenaeker, W. (1998) Density Functional Theory: A Source of Chemical Concepts and a Cost-Effective Methodology for Their Calculation. In: Advances in Quantum Chemistry, Elsevier, Amsterdam, Vol. 33, 303-328. https://doi.org/10.1016/S0065-3276(08)60442-6

[41] Parr, R.G., Donnelly, R.A., Levy, M. and Palke, W.E. (1978) Electronegativity: The Density Functional Viewpoint. The Journal of Chemical Physics, 68, 3801-3807. https://doi.org/10.1063/1.436185

[42] Hansch, C., Sammes, P.G. and Taylor, J.B. (1990) Computers and the Medicinal Chemist. In: Comprehensive Medicinal Chemistry, Pergamon Press, Oxford, Vol. 4, 33-58.

[43] Franke, R. (1984) Theoretical Drug Design Methods. Elsevier, Amsterdam.

[44] Microsoft $^{\oplus}$ Excel $^{\oplus} 2013$ (15.0.4420.1017) MSO (15.0.4420.1017) 64 Bits (2013) Partie de Microsoft Office Professionnel Plus.

[45] XLSTAT Version 19.5.47062 (64 bit) Copyright 1995-2018 (2018) XLSTAT and Adding software Registered Trademarks of Addinsoft. https://www.xlstat.com

[46] Huheey, J.E. (1965) The Electronegativity of Groups. The Journal of Chemical Physics, 69, 3284-3291. https://doi.org/10.1021/j100894a011

[47] Politzer, P. (1987) A Relationship between the Charge Capacity and the Hardness of Neutral Atoms and Groups. The Journal of Chemical Physics, 86, 1072-1073. https://doi.org/10.1063/1.452296

[48] Chattaraj, P.K., Cedillo, A. and Parr, R.G. (1996) Chemical Softness in Model Electronic Systems: Dependence on Temperature and Chemical Potential. Chemical Physics, 204, 429-437. https://doi.org/10.1016/0301-0104(95)00276-6

[49] Lipinski, C.A., Lombardo, F., Dominy, B.W. and Feeney, P.J. (2001) Experimental and Computational Approaches to Estimate Solubility and Permeability in Drug Discovery and Development Settings. Advanced Drug Delivery Reviews, 46, 3-26. https://doi.org/10.1016/S0169-409X(00)00129-0

[50] Vessereau, A. (1988) Méthodes statistiques en biologie et en agronomie. Tec et Doc 
Lavoisier, Paris.

[51] Snedecor, G.W. and Cochran, W.G. (1967) Statistical Methods. Oxford and IBH, New Delhi.

[52] Diudea, M.V. (2000) QSPR/QSAR Studies for Molecular Descriptors. Nova Science: Huntingdon, New York.

[53] Esposito, E.X., Hopfinger, A.J. and Madura, J.D. (2004) Methods for Applying the Quantitative Structure-Activity Relationship Paradigm. In: Methods in Molecular Biology, Humana Press, Totowa, Vol. 275, 131-213.

https://doi.org/10.1385/1-59259-802-1:131

[54] Eriksson, L., Jaworska, J., Worth, A.P., Cronin, M.T., McDowell, R.M. and Gramatica, P. (2003) Methods for Reliability and Uncertainty Assessment and for Applicability Evaluations of Classification- and Regression-Based QSARs. Environmental Health Perspectives, 111, 1361-1375. https://doi.org/10.1289/ehp.5758 